\title{
Clinical Features of Ectopic Thyroid Gland in Children: Single Center Experience
}

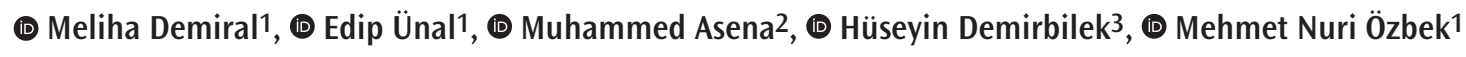

1Department of Paediatric Endocrinology, Gazi Yasargil Training and Research Hospital, Diyarbakır, Turkey

2Department of Paediatrics, Gazi Yasargil Training and Research Hospital, Diyarbakır, Turkey

3Department of Paediatric Endocrinology, Hacettepe University, Faculty of Medicine, Ankara, Turkey

\section{Abstract}

BACKGROUND/AIMS: Ectopic thyroid gland is the most common cause of permanent congenital hypothyroidism. Thus, this study aimed to examine the clinical and laboratory findings of patients with ectopic thyroid glands.

MATERIALS and METHODS: Age of diagnosis, gender, presenting symptoms, anthropometric measurements, capillary thyroid-stimulating hormone (TSH) in neonatal screening, venous TSH and free thyroxine (FT4), thyroglobulin, IQ score, thyroid gland imaging results, and treatment doses were extracted from the patients' hospital files.

RESULTS: Thus study included 26 patients (Female: 20) with the diagnosis of ectopic thyroid. The mean age of the diagnosis in patients born before the neonatal screening program (68.22 \pm 59.02 months) was higher than those born after neonatal screening $(1.32 \pm 1.41)(p<0.001)$. All patients had overt or subclinical hypothyroidism. The most common localization was the sublingual thyroid gland, which was detected in 23 patients (88.4\%). The molecular genetic analysis of 16 patients with persistently elevated TSH and FT4 did not detect thyroid hormone receptor beta (TR $\beta$ ) gene mutation. The Cattel intelligence test scores were within normal ranges, except for one case that had been diagnosed at the age of 4 years. Patients who had been diagnosed at the neonatal screening program had a better final height standard deviation score $(p=0.018)$ but without differences in the Cattel intelligence test scores $(p=0.373)$. TSH was normal in the sample of neonatal screening in one patient $(\mathrm{TSH}=1.2 \mu \mathrm{IU} / \mathrm{mL})$.

CONCLUSION: The majority of our patients with ectopic thyroid gland was female and had sublingual thyroid gland. Delayed diagnosis of overt and subclinical hypothyroidism due to neonatal screening unavailability, did not affect the psychomotor development but caused poor growth outcome. Neonatal screening cannot always detect the ectopic thyroid gland.

Keywords: Ectopic thyroid gland, neonatal screening, neurodevelopmental outcome, growth retardation, TR $\beta$ gene mutation

To cite this article: Demiral M, Ünal E, Asena M, Demirbilek H, Özbek MN. Clinical Features of Ectopic Thyroid Gland in Children: Single Center Experience. Cyprus J Med Sci 2021;6(Suppl 1):69-74

ORCID iDs of the authors: M.D. 0000-0002-0535-4954, E.Ü. 0000-0002-9809-0977, M.A. 0000-0002-0033-8672, H.D. 0000-0001-6374-5884,

M.N.Ö. 0000-0002-3203-741X 


\section{INTRODUCTION}

Dysgenetic thyroid gland accounts for $80 \%-85 \%$ of patients with permanent congenital hypothyroidism $(\mathrm{CH})$. The ectopic thyroid gland constitutes $60 \%$ of dysgenesis ${ }^{(1)}$ and can be detected at any age, with an average age of 40.5 years for all age groups ${ }^{(2)}$. Age upon diagnosis in childhood peaks in two periods: $1-2$ years and $4-5$ years $^{(3)}$. Children with a missing diagnosis at the neonatal period are presented later in life with the symptoms of hypothyroidism or compression depending on the thyroid gland localization. Growth retardation is the most common presenting feature in childhood. Additionally, lingual, sublingual, and laryngeal ectopic thyroid can cause bleeding, difficult intubation, and perioperative bleeding due to foreign body and upper airway obstruction, dyspnea, dysphagia, and superficial vein ulceration in the ectopic thyroid tissue ${ }^{(2,4-7)}$. The therapy of choice is L-Thyroxin, which is essential not only for hypothyroidism treatment but also for compressive symptom prevention by reducing gland size. Surgical treatment or I-131 ablation are recommended in patients with ectopic thyroid in severe compression/obstruction or bleeding despite appropriate L-Thyroxin therapy ${ }^{(8)}$.

During the organogenesis, disorders that result in a defective migration of the thyroid gland to its normal anatomical position account for the etiology of the ectopic thyroid gland. However, the etiopathogenesis has not been fully elucidated. Maternal anti-thyroid antibodies are suggested to cause a migration defect by agonistic effects on thyroid antigens. Additionally, some involved gene mutations (Nkx 21, Nkx 25, PAX8, FOXE1, and HHEX) in thyroid development and differentiation have been reported to cause an ectopic thyroid gland ${ }^{(2)}$. Furthermore, thyroid dysgenesis is suggested as a polygenic disease, which can be affected by various epigenetic factors ${ }^{(9-11)}$.

The most common locations of the ectopic thyroid gland include the lingual, sublingual, thyroglossal, pretracheal, laryngotracheal, laterocervical, submandibular, and retroperitoneal region, and rarely in esophagus, mediastinum, heart, aorta, adrenal glands, pancreas, gall bladder, and skin. Dual ectopia is extremely rare. Often one of the tissues is located in the lingual or sublingual region and the other in the subhyoid (usually) or suprahyoid region ${ }^{(9,12)}$. Persistent hyperthyrotropinemia $(\mathrm{PH})$ in treated thyroid dysgenesis children is a well-known situation ${ }^{(13)}$. It has been attributed to suboptimal therapy or abnormal setting of the thyroid hormones' negative feedback control of pituitary thyroid-stimulating hormone (TSH) secretion. Therefore, some case reports in the literature with $\mathrm{PH}$ were attributed to thyroid hormone receptor beta $(T R \beta)$ gene mutation in the ectopic thyroid gland $^{(14)}$. Thyroid hormone resistance (THR) is characterized by the unresponsiveness of the target organ to thyroid hormone. Loss of function mutations in the TR $\beta$ gene accounts for the underlying genetic etiology. Markedly elevated free thyroid hormone level and normal or slightly elevated TSH are the main hormonal features of THR. THR can rarely accompany to ectopic thyroid gland with an estimated frequency of 1: 140,000,000 (14). This study aimed to evaluate the clinical and laboratory findings of 26 patients who were diagnosed before and after neonatal screening program with the ectopic thyroid gland and investigate the presence of THR in patients with persistently elevated TSH and free thyroxine (FT4) under L-Thyroxin treatment.

\section{MATERIALS and METHODS}

Data of 26 patients with ectopic thyroid gland diagnosis between 2009 and 2019 in the Pediatric Endocrinology Department of a tertiary center hospital were retrospectively analyzed. The ethical approval was obtained from the local ethics committee (document no: 19.12.2019/398). An informed consent form was obtained from the parents of all children following the Declaration of Helsinki. Age upon diagnosis, gender, presenting symptoms, anthropometric measurements, capillary TSH value in neonatal screening, venous TSH and FT4, thyroglobulin value, thyroid gland imaging (ultrasound (USG)/scintigraphy) results, and treatment doses were extracted from the patients' hospital files. $T R \beta$ gene mutation analysis was performed in patients with persistently elevated TSH and FT4 despite appropriately adjusted L-Thyroxin dose. The Cattel intelligence test was performed in patients older than 6 years to evaluate the IQ score. TSH and FT4 levels were analyzed on the Abbott Architect i8000 device using the Electrochemiluminescence Immunoassay method. Normal ranges were $0.35-4.94 \mu \mathrm{IU} / \mathrm{mL}$ for TSH and $0.70-1.48 \mathrm{ng} / \mathrm{dL}$ for FT4. Thyroid scintigraphy was performed using 2-4 mCi Tc ${ }^{99}$ pertechnetate. Ectopic thyroid gland was defined as abnormal thyroid localization in scintigraphy, which was confirmed using a correlative USG once applicable.

\section{Statistical Analysis}

Statistical analyses were performed using International Business Machines Statistical Package for the Social Sciences Statistics for Windows, version 21 (IBM Corp., Armonk, N.Y., USA). Continuous variables were presented as mean \pm standard deviation (SD), whereas categorical variables were presented as number and percentage (\%). The Shapiro-Wilk test was used for the normality data distribution. The comparison of patients who were born before and after the neonatal screening program was made using the Student's $t$-test for normally distributed values and the Mann-Whitney $U$ test for non-normally distributed data. A $p$-value of $<0.05$ was considered statistically significant.

\section{Molecular Genetic Analysis}

Genomic DNA of patients was extracted from the peripheral blood using a MagPurix Blood DNA Extraction Kit by MagPurix 12 (Zinexts Life Science Corp., Taiwan) following the manufacturer protocol. All coding exons of the TR $\beta$ gene and their flanking 
splice site junctions were amplified by polymerase chain reaction using custom-designed primers. The libraries were prepared with the Nextera V2 kits (Illumina Inc.) following the manufacturer's instructions. Next-gene sequencing was carried on the MiSeq platform (Illumina, San Diego, CA, USA). Results were analyzed according to alignments of $T R \beta$ gene transcript (NM_000461.4) via Geneticist Assistant software.

\section{RESULTS}

A total of 26 patients with ectopic thyroid gland (20 females) diagnoses were recruited. The mean age of patients was 39.32 \pm 55.5 months (0.1-192). The clinical and laboratory features of patients are shown in the table. Since 2006, our country has had a national neonatal screening program based on capillary TSH measurement in blood spots. Eleven patients were admitted due to elevated TSH levels in neonatal screening. Of 12 patients who were born after the screening program had launched, 11 have high TSH in blood spots obtained for neonatal screening. The average capillary TSH was $82.23 \pm 33.24 \mu \mathrm{IU} / \mathrm{mL}(1.2-105)$. TSH was normal in the sample of neonatal screening in one patient (TSH $=1.2 \mu \mathrm{IU} / \mathrm{mL}$ ). Of whom, the diagnosis of $\mathrm{CH}$ and sublingual thyroid gland was considered during an outpatient clinical visit at the age of 2 months, where an elevated TSH was detected in venous TSH measurement.

Of 26 patients, 23 have first venous TSH above the upper detectable limit of $100 \mu \mathrm{IU} / \mathrm{mL}$, whereas $<30 \mu \mathrm{IU} / \mathrm{mL}$ in the remaining three patients. Patients who were born before the neonatal screening program had lower venous TSH values compared to those diagnosed during neonatal screening $(p=$ 0.03 ). Mean FT4 was $0.47 \pm 0.23 \mathrm{ng} / \mathrm{dL}$ (ranges $0.1-0.9$ ) and the mean thyroglobulin level was $117.62 \pm 147.63 \mathrm{ng} / \mathrm{mL}$ (ranges 5.1-482). Scintigraphy detected the sublingual thyroid gland in 23 out of 26 (88.4\%) patients, lingual in 1 (3.8\%), and submental thyroid in 1 (3.8\%), whereas thyroid scintigraphy could not be performed in 1 patient who was on L-Thyroxin therapy at admission. Thyroid USG did not observe the thyroid gland in normal localization but the upper line of the trachea. Psychomotor development was normal in all patients, except for one patient who was diagnosed at 4 years old. This patient had a mild learning disability and IQ score at the lower normal limit in the Cattel intelligence test.In 16 patients with a persistently elevated TSH and FT4 during follow-up, mutation analysis for the TR $\beta$ gene was performed, and no mutation was detected. TSH and FT4 levels of 16 children were shown in Figure 1.

The mean age upon diagnosis for patients born before the neonatal screening program was $68.22 \pm 59.02$ months. Of whom, 10 patients were admitted to the clinic due to growth retardation, 1 with prolonged jaundice, 1 with speech delay, and 2 with elevated TSH level in a routine laboratory examination (Figure 2). Patients who were born before the neonatal screening program, thereby with diagnosis delay, had lower final height and weight SD scores compared to those diagnosed during neonatal screening ( $p=0.018, p=0.016$, respectively). However, no statistically significant difference was found in the Cattel intelligence test scores, FT4 and thyroglobulin levels at the diagnosis, and final L-Thyroxin doses $(p=0.373)$ (Table 1).

\section{DISCUSSION}

This study evaluated the clinical characteristics, diagnostic methods, neurodevelopmental outcome, and molecular genetics analysis of 26 patients (age range: 3 days-16 years old) with ectopic thyroid gland diagnosis and revealed a female predominance, with the majority of patients having sublingual thyroid gland. One of the 12 (8.3\%) patients who underwent neonatal screening had missing diagnoses. Our study, to the best

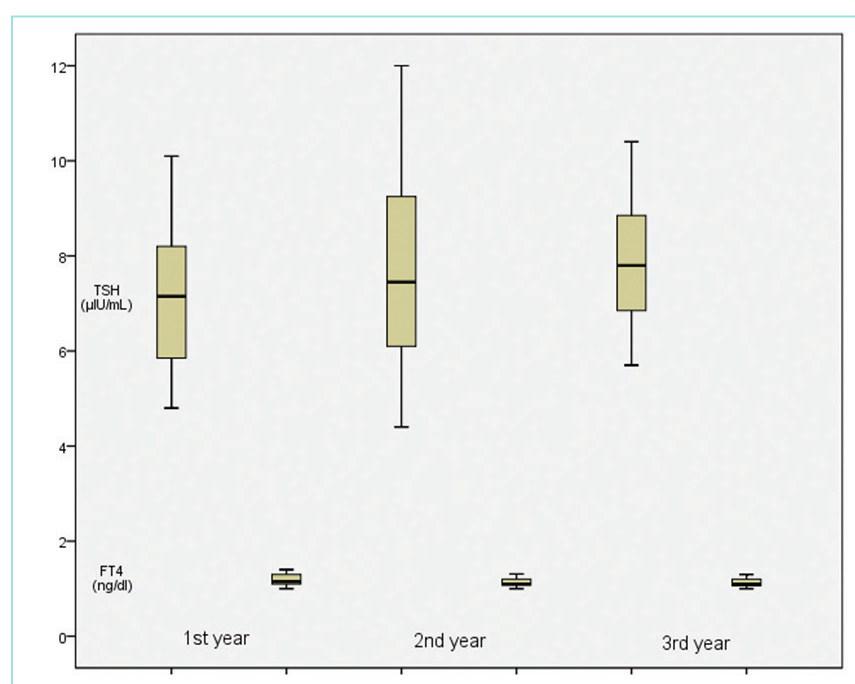

Figure 1. TSH and FT4 levels of 16 children with persistently elevated TSH and FT4.TSH, Thyroid-stimulating hormone; FT4, Free T4.

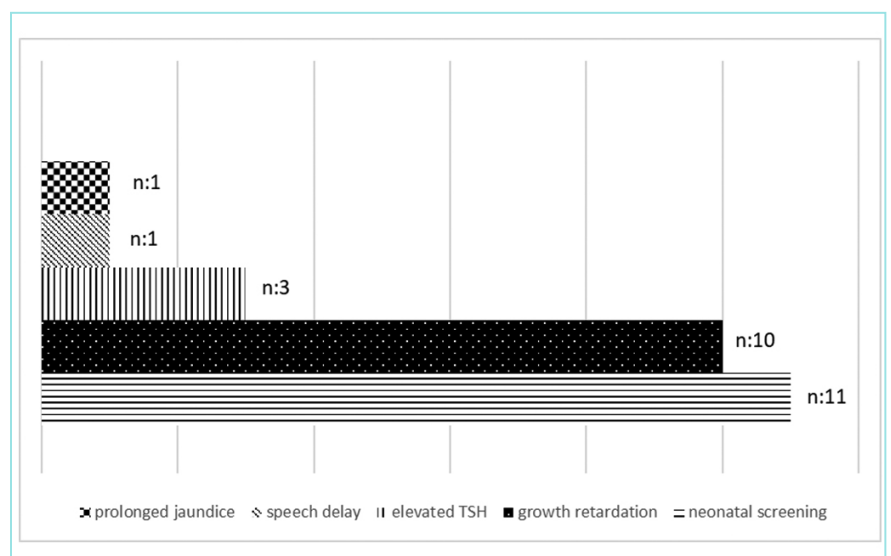

Figure 2. Manifestations of children with the ectopic thyroid gland.

n: Number 


\begin{tabular}{|c|c|c|c|c|}
\hline & $\begin{array}{l}\text { Neonatal screeningavailable } \\
\text { (mean } \pm \text { SD) }\end{array}$ & $\begin{array}{l}\text { Neonatal screening not available } \\
\text { (mean } \pm \text { SD) }\end{array}$ & p-value & $\begin{array}{l}\text { Total } \\
(\text { mean } \pm S D)\end{array}$ \\
\hline $\begin{array}{l}\text { Capillary TSH } \\
(\mu \mathrm{IU} / \mathrm{mL})\end{array}$ & $82.18 \pm 33.25$ & - & - & $82.18 \pm 33.25$ \\
\hline Age of diagnosis (month) & $1.32 \pm 1.41$ & $68.22 \pm 59.02$ & $<0.001^{* *}$ & $39.92 \pm 55.56$ \\
\hline $\begin{array}{l}\text { Venous FT4 } \\
\text { (ng/dL) }\end{array}$ & $0.44 \pm 0.21$ & $0.45 \pm 0.23$ & $0.36^{*}$ & $0.44 \pm 0.22$ \\
\hline $\begin{array}{l}\text { Venous TSH } \\
(\mu \mathrm{IU} / \mathrm{mL})\end{array}$ & $108.33 \pm 20.41$ & $88 \pm 28.02$ & $0.03 *$ & $95.17 \pm 29.25$ \\
\hline Thyroglobulin (ng/mL) & $181.83 \pm 187.56$ & $57.18 \pm 62.39$ & $0.135^{*}$ & $110.60 \pm 142.15$ \\
\hline Current age(year) & $6.12 \pm 3.48$ & $12.3 \pm 3.91$ & $<0.001 * *$ & $9.69 \pm 4.81$ \\
\hline Current height SD & $-0.45 \pm 1.14$ & $-1.99 \pm 1.84$ & $0.018^{* *}$ & $-1.34 \pm 1.74$ \\
\hline Current weight SD & $-0.2 \pm 1.16$ & $-1.18 \pm 2.2$ & $0.016^{* *}$ & $-0.76 \pm 1.87$ \\
\hline $\begin{array}{l}\text { Current L-thyroxine dose } \\
\text { ( } \mu \mathrm{g} / \mathrm{kg} / \text { day) }\end{array}$ & $3.08 \pm 1.18$ & $3.48 \pm 1.61$ & $0.571 * *$ & $3.31 \pm 1.43$ \\
\hline IQ score & $101.28 \pm 18.77$ & $98.93 \pm 14.88$ & $0.373^{* *}$ & $99.68 \pm 15.8$ \\
\hline
\end{tabular}

of our knowledge, is the first study that evaluated the clinical features and long-term outcome of patients with the ectopic thyroid gland and compared patients born before and after the neonatal screening program.

All large series that evaluated patients with ectopic thyroid reported a female predominance with ratios ranging between $61 \%$ and $88 \%(4-7)$. Our series revealed a similar rate of female predominance (76\%). The exact mechanism for female predominance in patients with ectopic thyroid glands has not been fully elucidated.

Lingual thyroid is the most common form among ectopic thyroids ${ }^{(8)}$. The frequency of the sublingual thyroid gland has been reported as $47 \%{ }^{(4)}, 34.6 \%{ }^{5)}, 17 \%\left({ }^{(6)}\right.$, and $53 \%{ }^{(7)}$. Our patient group, unlike other studies, reported $88.3 \%$ sublingually and $3.8 \%$ lingually located ectopic thyroids. The discrepancy between the lingual and sublingual thyroid ratios could be related to the underlying genetic and epigenetic etiologies that cause migration abnormalities during organogenesis.

The mean age upon diagnosis of patients born before the neonatal screening program (68.22 \pm 59.02 months) was higher than those born after the program. No difference was found in Cattel intelligence test scores, FT4, thyroglobulin, and final L-Thyroxin dose among those who are born before and after the screening program (Table 1). Growth retardation was more prominent in patients who were born before the screening program. Despite achieving euthyroidism, after an average of 7-year follow-up, patients who were diagnosed earlier in neonatal screening had a better growth outcome compared to those without neonatal screening. However, no difference was found in psychomotor development, which suggested that a small thyroid gland might produce well-enough thyroid hormone and achieve a thyroid hormone value that can prevent neurodevelopmental delay but does not appear to achieve appropriate growth.

Compression symptoms in the lingual thyroid are more common than sublingual thyroid(4). None of our patients had any signs of compression due to ectopic thyroid, which was attributed to the higher frequency of sublingual thyroid and the lower mean age upon diagnosis compared to the cases reported in the literature.

Patients with ectopic thyroid gland usually have an elevated TSH upon diagnosis in the neonatal period. Neonatal screening programs reported a broad range from 15 to $144 \mathrm{mIU} / \mathrm{L}$ of average TSH of patients with the ectopic thyroid gland ${ }^{(15,16)}$. Therefore, in TSH-based neonatal screening programs, there is a risk of missing the diagnosis of the ectopic thyroid gland, which has been reported as $1.6 \%$ in lingual thyroid ${ }^{(3)}$. A study that evaluated the French neonatal screening program results in 
9 years revealed that 50 patients missed the diagnosis. Of those patients, 23 (4 with agenesis and 11 with ectopic thyroid) have TSH below the cut-off value assigned in the screening program ${ }^{(17)}$. Capillary TSH, which was examined twice in our patients in the national neonatal screening program, was normal in $1(8.3 \%)$ of 12 patients (first sample TSH of 1.2, second sample TSH of 0.01 ). This patient was diagnosed with sublingual thyroid at the age of 2 months after the measurement of high TSH in an outpatient clinical visit. The mean TSH level was $82.23 \pm 33.24$ $\mathrm{mIU} / \mathrm{L}$ in the remaining 11 patients. Similar to the literature, our patients have a high mean capillary TSH level, except for the case with a missing diagnosis. However, despite the low cut-off TSH value assigned in our neonatal screening program ( $4.5 \mathrm{mIU} / \mathrm{L}$ ) compared to many screening programs, the rate of missed diagnosis of ectopic thyroid in the screening program was $8.3 \%$ $(1 / 12)$ that was higher than those reported in the literature. Furthermore, an autopsy study involving 200 cases reported a $10 \%$ frequency of ectopic thyroid ${ }^{(3)}$. This high rate of ectopic thyroid gland suggests much more cases with missing diagnosis and a higher exact frequency of ectopic thyroid gland than those reported in the literature.

Scintigraphy, which requires high TSH levels during scanning, is the gold standard in ectopic thyroid diagnosis. Many centers performed scintigraphy at a later age when treatment is ceased. Those centers claim that ectopic thyroid diagnosis or agenesis does not change the treatment approach. Contrarily, USG is suggested as a non-invasive method, which is easily accessible, distinguishes between structural anomaly and normal gland, and gives information about thyroid size. Additionally, detection of vascularization in ectopic thyroid tissue in cervical USG increases the diagnostic sensitivity ${ }^{(2)}$. However, we do not entirely agree with this approach. Elevated TSH does not affect individuals with thyroid agenesis but stimulates the thyroid gland, which causes enlargement, thereby increasing the risk of compression. Therefore, scintigraphy and correlative ultrasound or vice versa are recommended as an adjunctive tool in case the first test does not provide adequate information about the localization as well as the size of the thyroid gland.

Hypothyroidism is detected in 33\%-62\% of patients with ectopic thyroid ${ }^{(8)}$. Hyperthyroidism and thyrotoxicosis have also been reported very rarely ${ }^{(4)}$. All our patients had overt or subclinical hypothyroidism at diagnosis. The rate of hypothyroidism was higher than that reported in the literature. Patients with euthyroid at birth may progress to overt or subclinical hypothyroidism in case of increased thyroid hormone requirement and accelerated growth such as puberty, pregnancy, trauma, and infection ${ }^{(1)}$.

$\mathrm{PH}$ is a common problem during $\mathrm{CH}$ treatment. Factors, which might contribute to $\mathrm{PH}$, include an inadequate dose of L-Thyroxin, patient's noncompliance, and incomplete maturation of feedback mechanism that regulates TSH secretion. TSH levels usually stabilize after the first year of treatment. PH has been shown in $20 \%-40 \%$ of infants with $\mathrm{CH}$. However, it persists in $10 \%$ of these patients to childhood ${ }^{(18)}$. THR and ectopic thyroid can rarely coexist with $\mathrm{PH}$. The etiopathogenesis of the co-existence of these two rare entities is unknown. Retinoid X receptor (RXRs), a heterodimer of the thyroid hormone receptor, plays a key role in embryonic development and organogenesis. Therefore, the relationship between mutant $T R \beta$ and RXRs during thyroid organogenesis has been speculated to create a dominantnegative effect, thereby causing dysgenetic thyroid gland ${ }^{(19)}$.

There are four patients with the ectopic thyroid gland and THR in the literature ${ }^{(14,19-21)}$, of whom three showed TR $\beta$ mutation. TR $\beta$ mutation analysis was performed in 16 patients with persistently elevated TSH and FT4 during follow-up, and mutation was not detected in any of those patients. Therefore, the persistent high TSH and FT4 are attributed to treatment noncompliance.

This study has some limitations. It was a retrospective study. Previously, when the TSH value was $>100 \mathrm{mIU} / \mathrm{L}$, the quantitative value could not be measured. Thus, the initial serum TSH value of some patients was unknown.

Therefore, in our series of 26 patients, the majority with ectopic thyroid glands were female with a predominance of sublingual thyroid. Some patients cannot be detected in the newborn screening program since capillary TSH in the neonatal screening can be below the cut-off value. In patients with ectopic thyroid who are born before the start of the neonatal screening program, overt or subclinical hypothyroidism did not affect the neurodevelopmental outcome but led to a poor growth prognosis. Patients with biochemical THR did not genetically confirm this situation, which made this association controversial and suggested to be co-incidental in previously reported cases.

\section{Main Points}

- The ectopic thyroid gland is the most common cause of permanent congenital hypothyroidism.

- Neonatal screening cannot always detect the ectopic thyroid gland.

- Subclinical hypothyroidism due to the ectopic thyroid gland may not affect the neurodevelopmental outcome but lead to poor growth prognosis in children.

\section{ETHICS}

Ethics Committee Approval: The ethical approval was obtained from the Gazi Yaşargil Training and Research Hospital Ethics Committee (document no: 19.12.2019/398).

Informed Consent: An informed consent form was obtained 
from the parents of all children following the Declaration of Helsinki.

Peer-review: Externally peer-reviewed.

\section{Authorship Contributions}

Conception: M.D., E.Ü., M.A., H.D., M.N.Ö.; Design: M.D., E.Ü., M.A., H.D., M.N.Ö.; Supervision: M.D., E.Ü., M.A., H.D., M.N.Ö.; Materials: M.D., E.Ü., M.A.; Data Collection and/or Processing: M.D., E.Ü., M.A.; Analysis and/or Interpretation: M.D., H.D., M.N.Ö.; Literature Search: M.D., H.D., M.N.Ö.; Writing: M.D., H.D., M.N.Ö.; Critical Review: M.D., H.D., M.N.Ö.

\section{DISCLOSURES}

Financial Disclosure: The author declared no financial support for this study.

Conflict of Interest: The authors declared no conflict of interest.

\section{REFERENCES}

1. Kocova M, Zdraveska N, Zdravkovska M, Anastasovska V, Pop Gjorceva D. Submental thyroid ectopy might cause subclinical hypothyroidism in early childhood. SAGE Open Med Case Rep. 2016;4:2050313X16683623.

2. Noussios G, Anagnostis P, Goulis DG, Lappas D, Natsis K. Ectopic thyroid tissue: anatomical, clinical, and surgical implications of a rare entity. Eur J Endocrinol. 2011;165:375-382.

3. Gillis D, Brnjac L, Perlman K, Sochett EB, Daneman D. Frequency and characteristics of lingual thyroid not detected by screening. I Pediatr Endocrinol Metab. 1998;11:229-233.

4. Patil M, Ayyar V, Bantwal G, Raman A, George B, Mathew V. Thyroid ectopia: A case series and literature review. Thyroid Res Pract. 2015;12:110-115.

5. Yoon JS, Won KC, Cho IH, Lee JT, Lee HW. Clinical characteristics of ectopic thyroid in Korea. Thyroid. 2007;17:1117-1121.

6. Gu T, Jiang B, Wang N, et al. New insight into ectopic thyroid glands between the neck and maxillofacial region from a 42-case study. BMC Endocr Disord. 2015;15:70.

7. Gopal RA, Acharya SV, Bandgar T, Menon PS, Marfatia H, Shah NS. Clinical profile of ectopic thyroid in Asian Indians: a single-center experience. Endocr Pract. 2009;15:322-325.

8. Dutta D, Kumar M, Thukral A, et al. Medical management of thyroid ectopia: report of three cases. J Clin Res Pediatr Endocrinol. 2013;5:212-215.
9. Amani Mel A, Benabadji N, Benzian Z, Amani S. Ectopic lingual thyroid. Indian J Nucl Med. 2012;27:124-126.

10. Cerqueira TLO, Ramos YR, Strappa GB, et al. Mutation screening in the genes PAX-8, NKX2-5, TSH-R, HES-1 in cohort of 63 Brazilian children with thyroid dysgenesis. Arch Endocrinol Metab. 2018;62:466-471.

11. Santangelo G, Pellino G, De Falco N, et al. Prevalence, diagnosis and management of ectopic thyroid glands. Int J Surg. 2016;28(Suppl 1):S1-S6.

12. Tucker D, Woods G, Langham S, Biassoni L, Krywawych S, Hindmarsh P, Peters C. The incidence and clinical features of dual thyroid ectopia in congenital hypothyroidism. J Clin Endocrinol Metab. 2016;101:2063-2068.

13. Bagattini B, Cosmo CD, Montanelli L, et al. The different requirement of L-T4 therapy in congenital athyreosis compared with adult-acquired hypothyroidism suggests a persisting thyroid hormone resistance at the hypothalamic-pituitary level. Eur J Endocrinol. 2014;171:615-621.

14. Grasberger H, Ringkananont U, Croxson M, Refetoff S. Resistance to thyroid hormone in a patient with thyroid dysgenesis. Thyroid. 2005;15:730-733.

15. Olivieri A, Corbetta C, Weber G, Vigone MC, Fazzini C, Medda E. Italian Study Group for Congenital Hypothyroidism. Congenital hypothyroidism due to defects of thyroid development and mild increase of TSH at screening: Data from the Italian National Registry of infants with congenital hypothyroidism. J Clin Endocrinol Metab. 2013;98:1403-1408.

16. Perry RJ, Maroo S, Maclennan AC, Jones JH, Donaldson MD. Combined ultrasound and isotope scanning is more informative in the diagnosis of congenital hypothyroidism than single scanning. Arch Dis Child. 2006;91:972-976.

17. Leger J. Screening for congenital hypothyroidism in France. Misdiagnosed cases: collaborative study of screening centres in France. Eur J Pediatr. 1990;149:605-607.

18. Fisher DA, Schoen EJ, La Franchi S, et al. The hypothalamic-pituitarythyroid negative feedback control axis in children with treated congenital hypothyroidism. J Clin Endocrinol Metab. 2000;85:2722-2727.

19. Heather N, Hall K, Neas K, Potter H, Wiltshire E. Growth and development in a child with resistance to thyroid hormone and ectopic thyroid gland. Pediatrics. 2012;129:e817-e820.

20. Nakajima Y, Yamada M, Horiguchi K, et al. Resistance to thyroid hormone due to a novel thyroid hormone receptor mutant in a patient with hypothyroidism secondary to lingual thyroid and functional characterization of the mutant receptor. Thyroid. 2010;20:917-926.

21. Guo ML, Zheng X, Yang LX, Qiu YL, Cheng L, Ma SG. Coexistence of resistance to thyroid hormone and ectopic thyroid: ten-year follow-up. Arch Endocrinol Metab. 2016;60:601-604. 